QUADERNS DE FILOSOFIA VOL. IV NÚM. I (20I7): 27-45

eISSN: 234I-3042 DOI: I 0.7203/QFIA.4.I.9209

José Antonio Marín-Casanova

Universidad de Sevilla

\title{
La filosofía como descarga de la sobrecarga de innovación
}

(Philosophy as unloading of innovation overload)

Resumen: Se ensaya la tesis de que no habiendo innovación sin tradición, la filosofía opera en un espacio en tensión entre estos dos polos. Se comienza trazando un recorrido por las distintas precomprensiones de la naturaleza y el conocimiento en la Antigüedad y en la Modernidad como esquemas del contraste entre tradición e innovación; a continuación, se acude a Ortega y Gasset y a Heidegger para precisar en qué consiste la innovación en filosofía y para explicitar su conexión con y dependencia de la tradición; por último, se propone explorar la innovación educativa de la filosofía como, siguiendo a Odo Marquard, descarga compensatoria de la sobrecarga innovativa.

Abstract: This paper claims that insofar as there is no innovation without tradition, philosophy operates in a space of tension between those two poles. I begin by sketching different pre-understandings of nature and knowledge in Antiquity and Modernity as schemas of the contrast between tradition and innovation. I then resort to Ortega y Gasset and Heidegger to specify what innovation consists of in philosophy and to explain its connection with and dependence on tradition. I finally propose to understand, following Odo Marquard, educative innovation in philosophy as a compensatory unloading of innovation overload.

Palabras clave: innovación, tradición, Ortega y Gasset, Heidegger, Marquard. Keywords: innovation, tradition, Ortega y Gasset, Heidegger, Marquard. 
$\mathrm{E}$ N UN PRINCIPIO, Filosofía e innovación se repelen mutuamente, tanto es así que hablar de "Filosofía de la innovación" comporta en términos históricos originales un genuino oxímoron. Sin embargo, hoy día la innovación es poco menos que un prerrequisito de la Filosofía; al menos, de la Filosofía académica. Que se celebren congresos filosóficos internacionales sobre la innovación educativa en Filosofía como tópico focal es índice ilustrativo suficiente de ello. ¿Cómo es posible que la innovación haya pasado de condición de casi imposibilidad a casi condición de posibilidad de la Filosofía? Para entender el tránsito modal conviene percatarse del doble sentido del genitivo en el sintagma "Filosofía de la innovación". Se trata de leer ese complemento del nombre, primero, en el sentido objetivo, en el de la constitución de la innovación en objeto filosófico, toda vez que la actual e "incuestionable" mentalidad innovadora choca con la mentalidad filosófica clásica, siendo, en cambio, tributaria de la mentalidad bíblica e identificándose, por lo demás, con la mentalidad moderna, en tanto que réplica secularizada del imaginario religioso. De hecho, el programa de la Modernidad, con las armas culminantes de la Teodicea, canoniza el imaginario innovador haciendo de la variación de la sabiduría una obligación, la obligación, también moral, de innovar. Ahora bien, cuando la innovación es objeto de la Filosofía se termina produciendo el efecto, sintomático primero y casi automático luego, de la imposición de la lectura subjetiva del genitivo de marras. En efecto, cuando la Filosofía llega a tomar en cuenta la innovación como objeto suyo, caemos en la cuenta de que es la misma Filosofía la que se torna innovadora: hacer Filosofía de la innovación (genitivo objetivo) comporta hacer innovación de la Filosofía (genitivo subjetivo). Ahora bien, la innovación no es algo exento sin más, que se pueda leer unilateralmente, solo en el sentido subjetivo del genitivo, como preferentemente se tiende a hacer hoy, sino que lo es por referencia a una tradición. Sin una previa continuidad, la innovación se queda en pedalada en el vacío. Quizá sea lo breve de la vida el motivo antropológico que explique esta aparente paradoja: la muerte, su rapidez, limita nuestra capacidad de innovación. Cualquier innovación requiere de conexión con lo dado en la tradición. Y ello se hace más perentorio con la discontinuidad moderna, con la aceleración de los tiempos modernos. La falta de tiempo que resulta constitutiva del animal humano se hace, además, especialmente consecutiva al humano moderno. Semejante prisa nos hace pensar, por contraposición, que acaso se pueda dar una oculta innovación educativa en Filosofía y que tal vez pueda y deba explotarse paradójicamente como una lenta descarga de la apresurada sobrecarga innovativa. 
Ciertamente, desde el horizonte hermenéutico clásico, como el sentido de lo que se tiene por real es cosmológico, la novedad carece de lugar natural. $\mathrm{Y}$ es que si hay un prejuicio constituyente del pensamiento filosófico, su premisa fundacional, y resistente al paso del tiempo, es que nada surge de la nada (North 2015) y que, en consecuencia, lo nuevo es naturalmente imposible. En el plano ontológico, lo nuevo, accidente insubstancial, es un hecho sin valor, un disvalor incluso. La innovación no solo no es natural, sino contranatural. La razón de ello reside en que en la perspectiva filosófica clásica la naturaleza se viene a concebir como autónoma, absoluta e incondicionada. La physis tiene en sí su norma necesaria, todo es relativo a ella, nada la condiciona, ella condiciona todo: es absoluta. La naturaleza griega es el límite necesario, el horizonte intraspasable de toda acción humana. Sea de la índole que sea — sea, pues, teórica, práctica o técnica一, la acción rebota necesariamente en el inmutable muro vertical de la naturaleza. Dado que el orden de la naturaleza es necesario, dado que todo es conforme a naturaleza, no hay propiamente espacios de innovación ontológica. No se puede cambiar lo que es natural. La naturaleza, que es causa omnímoda, no puede alterarse, no puede ser poseída, sino a lo sumo contemplada. De ahí que la acción más noble, la primera, sea la teoría. Brota de este planteamiento ontológico la concepción griega de la verdad como desvelamiento del orden cósmico natural, de cuya contemplación teórica nacen los conocimientos que regulan las obras y los hechos humanos. La teoría se supraordina a la praxis y a la técnica. Esa primacía expresa la conciencia natural antigua, a saber, la conciencia cosmológica de que no se da acción correcta ya ética ya "poética", si no es conociendo las leyes inmutables que presiden la regularidad de los movimientos de la naturaleza. Y la acción del humano no puede modificar el orden cósmico, no tanto por la modestia, insuficiencia o precariedad de las disponibilidades técnicas, cuanto porque la naturaleza es preconcebida como inmutable y por eso mismo como indomenáble. No es que el griego tuviera poca capacidad material para la innovación por su precaria tecnología, sino que su tecnología era precaria por su escasa proclividad intelectual a la innovación. Y esta escasa capacidad innovadora es el pendant de la consideración de la naturaleza como paradigma de toda acción: son la ética y la técnica quienes tienen que mirarse en el modelo ejemplar natural para reparar respectivamente en las reglas del comportamiento "recto", del hacer "recto". Así pues, en el esquema de la cosmología clásica la técnica se inscribe en el registro de la verdad pensada no como dominio de la naturaleza, sino como su contemplativo desvelamiento. La naturaleza con su olímpica marca de necesidad no consiente a la técnica el traspasar su límite vertical ni, 
por consiguiente, tampoco permite al tiempo el configurarse como historia de la progresiva transformación de lo real, como innovación (MARÍN-CASANOva 20I 6, 33-8). Esto es algo que le estaba reservado a un genio distinto, y mucho, del filosófico, el espíritu religioso.

En efecto, en la precomprensión religiosa la naturaleza se figura como efecto de una voluntad, la de su omnipotente Creador. Crear el mundo es la acción que reúne superlativamente las dos características magnas de la innovación: la proactividad y la performatividad. Dios es autor, mediante el poder supremo del nombre, de la mayor innovación posible, la Creación. Su acción, depotenciadora de la naturaleza y su necesidad, es la hipérbole paradigmática de la innovación. Nada más innovador que reemplazar el sentido cosmológico de lo que hay por el sentido antropoteológico, y con ello, la conciencia natural por la conciencia histórica, el saber teórico por el saber operativo, la tragedia por el drama, la nostalgia por la esperanza, la necesidad por la contingencia, el logos por la voluntad. Además de ofrecer con la noción de Creación el ejemplo máximo de innovación, la fe religiosa "innova" la mentalidad trágica (NATOLI 2016A) abriendo el horizonte de la salvación, sin el cual la ciencia moderna no sería moderna (NATOli 20г6B). Y es que en la Modernidad se realiza la inversión del esquema clásico inaugurada por la innovación bíblica, toda vez que la actividad intelectual, que los griegos llamaban theoria y los latinos contemplatio, ya no fue pensada como el fin último al que subordinar el hacer político, sino como instrumento operativo. El programa baconiano, scientia est potentia, establece que el destino del saber es su funcionalidad al poder: el gran poder de hacer y de modificar la naturaleza en vista de la proyectualidad humana. Mientras que para los antiguos el conocimiento de la naturaleza se detenía delante de su inmodificabilidad, para los modernos, por el contrario, la naturaleza, absorbida por la intencionalidad, forma parte del proyecto de cambio humano: el proyecto se convierte en medida de un hacer cuya voluntad ya no asume la inmodificabilidad de la naturaleza como límite. La raíz de esta novedosa actitud innovadora no es griega, sino judeo-cristiana (GALIMBERTI 2000, 293-301). Según la tradición religiosa, Dios ha ubicado al humano en el mundo con el fin de que fuese su seńor y de que dominando el mundo hiciese obra de verdad. Pero esta verdad ya no es la verdad en la acepción griega de alétheia, que significa "desvelamiento" de las leyes inmutables de la naturaleza a la que se remite la teoría. Esta otra verdad es la verdad en la acepción hebrea de émet (amén), que significa hacer lo que Dios ha prescrito al hombre. Se trata entonces de una verdad que no se contrapone al "error" o la "falsedad", sino a la "infidelidad" al mandato divino y, así pues, a la ignavia, a la pigricia. Luego, a diferencia de la clásica verdad filosófica, la innovativa verdad religiosa no es cosa que se conozca, sino algo que se practica, una verdad no descriptiva o 
predictiva, sino proactiva y performativa. En este sentido san Juan "incurre" en el oxímoron de "hacer verdad" (Jn 3, 21; I Juan 1, 16). Desechando la verdad griega que se contempla, el esquema mental moderno viene a adoptar la verdad hebrea que se hace en el tiempo, con la consiguiente primacía indiscutible del hacer sobre el contemplar, de la innovación sobre la repetición. Cuando Francis Bacon somete el saber al poder y Karl Marx la interpretación del mundo a su transformación, aun bajo registros distintos, ambos están confirmando el "hacer verdad" religioso, que se despide definitiva e innovadoramente de la clásica contemplatividad teórica. Gozne de la tradición vetero y neotestamentaria es la voluntad de Dios (ORTega y Gasset 2006A, 19-21), la cual quiere el señorío del hombre sobre el mundo. "Hacer verdad", es decir, ser fieles a la orden de Dios, equivale entonces a derecho a dominar. La técnica, que ofrece las condiciones para el ejercicio de ese derecho, se inscribe en el horizonte teológico, donde Dios es el fundamento que justifica la bondad del operar técnico y su correspondiente obligatoriedad. De una verdad que se hace más que se contempla es exponente, por ejemplo, el mencionado proyecto tecno-científico baconiano, que expresa una fe incondicionada en las posibilidades del saberhacer con el fin de innovar, mejorándola, la propia condición del hombre. El programa que ese primer moderno ofreció no innovó apenas en cuanto a los resultados científicos concretos, pero estaba fuertemente animado por la convicción de que esa transformación tecno-científica del mundo no es algo que esté por suceder, sino de que es algo que debe suceder, que se debe hacer que suceda. Y es que cuando lo real ya no es "cosa”, sea piedra, sea planta, sea humano o sea astro, sino que es conducta, o sea, cuando "la verdadera realidad consiste en el comportamiento del hombre con Dios" (OrTega y Gasset 2006C, 471), en la praxis de la contingente y dependiente criatura humana con respecto a su divino Creador, entonces ya "ninguna de las categorías cósmicas del griego sirven para interpretar y describir esta extraña realidad" (OrTega y Gasset, 2006c, 471), toda vez que la praxis se supraordina a la teoría. De modo que el conocer adquiere una insobornable e insuprimible coloratura moral y religiosa: saber para poder dominar el mundo innovándolo en cumplimiento del deber asignado por Dios. Así, inscrito en un programa religioso, el proyecto de innovación que inaugura la Modernidad se piensa a sí mismo, por un lado, como ejecutor de un programa divino, y, por otro lado, como eficaz actuación de una tarea moral. En este orden de ideas, el poder cognoscitivo implícito en la "nueva ciencia" moderna se autocomprende como acto de humildad, como forma de expiación de esa culpa expresada en la soberbia intelectual del pecado original a la que no escapa la antigua especulación axiomática griega. Y al igual que esta última subordinaba el "hacer" al "ver contemplativo", cuyo objeto era una naturaleza en su conjunto inmutable, la ciencia moderna subordina el 
"ver" al "hacer manipulativo", que en las leyes de la naturaleza busca la huella divina, y en su descubrimiento las condiciones del rescate humano, de la "salvación” (Marín-Casanova 20i 6, 38-44).

Con el proactivo y performativo "saber que es poder", poder capaz de reducir todas las cosas a la medida del control humano, el mundo queda abierto de este modo a su omnímoda innovación. Se pone así en marcha el programa de la Modernidad, entendiendo por esta la era del carácter autoimpositivo de lo novum, donde el hecho de la novedad se transforma en un valor. Ese es el programa que iba a permitir la innovación con, valga el retruécano, la conversión del mal del devenir en el devenir del mal. El culmen teórico de tal programa novador quizá se encuentre en la Teodicea de Leibniz, en cuya frase "la sagesse doit varier" (\$124) se cifra, a mi entender, el lema vertebral de la Filosofía de la innovación. El caso es que la Providencia moderna no ama la pesadez de lo pretérito sino la ingravidez de lo futuro. Lo importante no es el provenir, sino el porvenir. Mientras el clásico quería repetir un mismo paradigma teniendo el pasado como modelo, queriendo hacerlo presente a ultranza, el moderno querrá innovar teniendo el futuro como modelo, queriendo hacerlo presente a ultranza. Se trata de variar a todo trance, a muerte, de modelar resueltamente el tiempo en una "época en la que se hace un valor determinante el hecho de ser moderno" (VATtimo 2000, 7), en un momento en que el mundo se acelera y se da el intento innovador de dominar la aceleración mediante el denominado "conformismo con la aceleración" (Beschleunigungskonformismus), produciendo una cuádruple positivización ontológica: de la mutabilidad, de la fugacidad, de la temporalidad y de la procesualidad (MARQUARD I986A, 60-4), la cual es, a mi juicio, la cuádruple premisa de la moderna mentalidad del progreso innovador. Y es que "como ley necesaria de la historia, el progreso implica la identidad axiológica entre melius y novus, esto es, la idea de que lo que es moderno, actual, es de por sí mejor que lo que ha pasado" (Chiurazzi I 999, 13). En definitiva, ser moderno, actualizar e innovar, es un deber, ya que "si la historia tiene este sentido progresivo, es evidente que tendrá más valor lo más 'avanzado' en el camino hacia la conclusión, lo que esté más próximo al término del proceso" (VATTIMO 2000, 8).

El intento innovador de dominar la aceleración mediante la conformidad con la misma aceleración comporta ciertamente cuatro premisas, que son las premisas que Marquard atribuye a la Teodicea: a) positivización ontológica de la mutabilidad, b) positivización ontológica de la fugacidad, c) positivización 
ontológica de la temporalidad y d) subjetivación "hipertribunalizadora" de la realidad. Aplicando libérrimamente el esquema marquardiano al respecto se puede comprender cabalmente cómo el concepto de progreso innovador se convirtió en una, puede que la principal, de las etiquetas de la Modernidad filosófica (MARÍn-CASANOva 20I6, 45-9).

La innovación comporta efectivamente la positivización ontológica de la mutabilidad, de la variabilidad, del cambio. La mentalidad clásica tomaba al movimiento como exponente conspicuo del mal: predicar el devenir de una cosa denotaba el carácter limitado de tal cosa, su imperfección, su maldad ontológica. El bien era inmutable e invariable, la estabilidad en sí. Pero en la Modernidad, y en ello el protagonismo correspondió al efervescente e imparable desarrollo de las ciencias naturales, se fue logrando crecientemente la prodigiosa capacidad de distanciarse del mal físico: las enfermedades y su dolor iban dejando de obedecer a encantamientos de diversa alquimia para entregarse a razones de una física sobre las que la mano de la técnica podía operar: la "quirurgia” desmalifica o bonifica el mal físico. La Metafísica de la innovación, por medio de la Teodicea, hará lo mismo con el mal metafísico, y en último término, en un proceso metamórfico cuyo eco resuena en la actualidad, cuando se nos responsabiliza hasta de nuestra propia fealdad, con los otros males: el mal gnoseológico, el mal moral y el mal estético. La Teodicea de Leibniz teleologiza el mal mediante la noción de compensación (el mal se encuentra compensado mediante el bien por todas partes) y el pensamiento bonum via malum (hay bien merced al mal). El mal tiene razón, una razón suficiente: ser condición de posibilidad del bien. Y esto es conjurar el mal, privarlo de su substancia, hacerlo naturalmente bueno. Originalmente. Con lo que el pecado original empalidece: la felix culpa deviene más felix que culpa, casi solo felix (MARQUARD I 98 I в, 45-7; I 98 ID). O dicho con rotundidad: no hay mal, solo bien. Lo que nos parece malo no es realmente malo, según el optimismo, sino expediente "permitido" por Dios para el mayor de los bienes: la libertad. De modo que en la Modernidad, donde todo fluye y se disuelve, termina también disolviéndose la estabilidad como medida ontológica. Ahora la medida es dinámica, la inestable, por definición, innovación: es el cambio entendido como progreso y evolución. El mundo moderno transita así del mal de la fluidez a la fluidez del mal. Haciendo de la necesidad virtud, conformismo con la aceleración por medio, la mutabilidad pasa de vicio a virtud, la virtud de la innovación.

Asociada a la de la mutabilidad se encuentra la positivización ontológica de la fugacidad o transitoriedad, de lo efímero y alterable. Al igual que le acontecía a la finitud, la vertiente del mal metafísico consistente en la caducidad encuentra refugio metamórfico en el relato de la Teodicea: el mal de la transitoriedad se convierte en la transitoriedad del mal. En el relato moderno 
lo transitorio, lo novedoso, la moda, se convierte en lo valioso. La innovación saluda arrobada lo efímero, y lo cultiva con alborozo. Lo que deviene siempre es bueno y lo que adviene es mejor, pues aproxima el presente de la historia a su meta. Es menester, con tal de alcanzar el objetivo último cuanto antes, acelerar sin demora la ignición de los navíos del progreso. Y comoquiera que la distancia más estrecha entre el momento actual y la meta futura es la Revolución, hay que emprenderla, como mal menor, como mal bueno, como quintaesencia del último mal, ya definitivamente bonificado, como el ultramalo superbien de la meta final de la historia. Haciendo de la necesidad virtud, conformismo con la aceleración por medio, la Revolución pasa de vicio a virtud, la virtud de la innovación.

Positivizado el cambio, y convertida en deber histórico la aceleración de la velocidad, también han de positivizarse ontológicamente las turbulencias del presente, incrementadas con ello: se hace preciso bonificar la temporalidad. El clasicismo filosófico condenaba la finitud en el tiempo de las cosas: la duración de algo señalaba su maldad ontológica. La novedad, su temporalidad, era considerada como feble, expresión de la debilidad o falibilidad de una cosa. El bien se asociaba, he ahí la contraposición, a la eternidad, al espacio donde no hay tiempo, pues era todo el tiempo, el transtiempo. El clásico entendía, por consiguiente, la novedad, su historicidad, como marcador de decadencia o degeneración. La Filosofía de la innovación, sin embargo, mediante el mecanismo optimizador del relato de la Teodicea, acoge entusiasmada el transcurso agitado de las novedades, invirtiendo la ontología de lo inmutable. Y es la innovación la que eso justifica, por cuanto lo turbulento del presente se explica como consecuencia de un largo pasado que teleológicamente ha estado operando con el fin de preparar un porvenir mejor del que las agitaciones actuales, las innovaciones, serán causa o medio. La dimensión temporal es por ello imprescindible cauce para el despliegue universal del género humano. Con lo que, haciendo de la necesidad virtud, conformismo con la aceleración por medio, la temporalidad pasa de vicio a virtud, la virtud de la innovación.

La innovación representa, por último, la expresión, por antonomasia, del carácter procesal o "tribunalizador" de los tiempos modernos. La Modernidad comienza sospechando de todo, poniendo en duda la legitimidad de cualquier cosa presente. Todo ha de mostrar o exhibir su credencial de inocencia ante el tribunal más alto, el Tribunal Supremo de la Razón, lo que, servata distantia, hoy día viene a ser la agencia de evaluación correspondiente. Y bajo un presupuesto de este cuño la realidad (también la existencia, sobre todo, la académica) va resultando procesada cada vez más, vista como vista, vista judicial. La Teodicea avanza en esta dirección, en tanto que se atreve a obligar a Dios a tomar asiento en el estrado de los acusados para que dé razón del mal presente 
en su Creación. El proceso se saldará con la eliminación de (la necesidad de) su poder redentor, en tanto en cuanto el mal es teleologizado inmanentemente. En la misma Tierra hay una razón suficiente que lo legitima: la libertad de los hombres es la razón del mal. Pero a Dios le restaba aún el atributo de Creador. Lo perderá conforme el sujeto moderno se vaya constituyendo en yo trascendental que innova dictando los ucases de la objetividad: el yo idealista alemán desdiviniza el mundo y en paralelo simultáneo se diviniza a sí mismo: el yo se convierte en Dios. Ese ich, que se ha elevado a condición de posibilidad de toda experiencia, tanto natural como histórica, es el nuevo sujeto de la historia y llevará el nombre de "Género humano" o "Humanidad". Y al igual que la Teodicea le exigió a Dios dar cuenta del mal, también su mutación, la Filosofía de la Historia, o su trasunto contemporáneo, la Filosofía de la innovación, procesa al nuevo creador, la Humanidad. La innovación lleva consigo de este modo una suerte de "Antropodicea" (a la que sigue hoy sometido el académico como creador científico) donde el hombre tiene que defenderse de la imputación de responsabilidad por el mal (no solo el gnoseológico) en el mundo. La innovación acaba identificándose con el Juicio Universal. Y en este juicio el argumento de la defensa ha sido muchas veces el de acusar a los humanos, pero no a todos: los responsables son siempre los otros, nunca los activistas del bien por venir, los benefactores del futuro, la vanguardia innovadora. Con lo que, haciendo de la necesidad virtud, conformismo con la aceleración por medio, el proceso (el progreso) pasa de vicio a virtud, la virtud de la innovación.

Se comprende así que cuando la innovación es objeto de la Filosofía, y más si resulta objeto principal, se termina produciendo el efecto de la imposición de la lectura subjetiva del genitivo. Se pasa de la Filosofía de la innovación a la innovación de la Filosofía. En efecto, cuando cambiando de objeto la Filosofía llega a tomar en cuenta la innovación como objeto suyo, caemos en la cuenta de que cambia también el sujeto, de que es la misma Filosofía la que se torna innovadora: hacer Filosofía de la innovación (genitivo objetivo) comporta hacer innovación de la Filosofía (genitivo subjetivo). Quizá el plantearse el problema de la innovación educativa en Filosofía, es decir, que la innovación educativa en Filosofía se presente como problema capital de estudio, venga de preterir que el sentido del genitivo en el sintagma "Filosofía de la innovación" es doble. De modo que la lectura moderna, exclusivamente subjetiva, corre el riego de ideologizarse, de convertirse en innovatismo abigarrado que acabe, en último término, con la "entidad" filosófica, con el cuerpo histórico de la Filosofía. 
Quién sabe si el tan denunciado fenómeno actual del arrinconamiento de la Filosofía en los planes de estudios del mundo entero no obedece a una exacerbación del alma innovadora, que soslaya la tradición en la que se fragua la Filosofía de la innovación, que oblitera así la eventual "innovación oculta" (Cunningham 20i3-i4; Castro, Echeverría y Unceta 20i6), esa que se produce fuera del circuito $\mathrm{I}+\mathrm{D}+\mathrm{i}$, innovación subyacente en la propia historia de la Filosofía, haciendo del hecho de la sobrecarga de innovación un valor, un valor autoimpositivo... Y si ese problema tiene solución tal vez venga esta de no confundir más el hecho con el valor, de no omitir más el hecho de que la innovación lo es por referencia a una tradición.

Ahora bien, por mucho que el nuevo mito, el mito de lo nuevo, la innovación, se presente como relato totalizador, como configuración global de sentido, por más reticencia o rechazo que pueda provocarnos su frecuente ideologización, por desagradables que hoy puedan resultar las repercusiones de su abusiva puesta en práctica en todas partes, y especialmente en las académicas, cabe preguntarse, más allá del eventual gusto recalcitrante, si la innovación es necesaria. Y para ello, para responder a una pregunta sobre la necesidad humana de algo, lo mejor es confrontar esa presunta necesidad con la mayor necesidad humana: la necesidad de tiempo.

Precisamente es en la respuesta a semejante interrogante que reparamos en el hecho de que sin preservación no hay innovación que valga: la Filosofía de la innovación arraiga en un espacio que es el mismo que aquel en el que arraiga la Filosofía de la tradición, un espacio que es un tiempo o, más bien, una falta de tiempo. Y justo el tiempo es nuestro recurso más escaso y por ello el más valioso. Si algo nos falta, eso es tiempo. Y si nos falta, es porque moriremos. Nuestro futuro es la muerte: "Somos en tanto que habitamos en la vecindad de la muerte" (HEIDEgGer I997, 167). La muerte es nuestra mayor certeza, $y$, aunque no lo fuera, afecta a toda la humanidad: diacrónicamente la tasa general de mortalidad humana es del cien por cien. Y, antes o después, con conciencia o sin ella, la muerte, más fin que finalidad de la vida, siempre afecta prematuramente: Ars longa, vita brevis. La brevedad de la vida (MARQUARD I98 IC, 119; I994A; 20I3) nos torna impacientes, nos obliga a la rapidez, pues no podemos esperar demasiado para conseguir nuestros propósitos. Dejando pasar las oportunidades, dejamos pasar la vida. La muerte se anticipa siempre por definición, por la de-finición de nuestra finitud; por mucho que se retrase, llega antes de tiempo. Hay que apresurarse en arribar adonde queremos antes de que llegue la muerte. No podemos procrastinar en la consecución de las anheladas transformaciones. Las cosas nuevas deseadas debemos hacerlas deprisa, más pronto que tarde, pues si no, será demasiado tarde. El hambre de futuro hay que saciarla ya. A esta brevedad de la vida responde la innovación. 
Ahora bien, por paradójico que resulte, esa misma brevedad nos torna pacientes vitalicios, obligándonos a la lentitud. La rapidez de la muerte acorta nuestra capacidad de innovación. Los cambios experimentables son limitados por nuestra limitación esencial. Por eso toda transformación requiere de conexión: no vivimos tiempo bastante para renovar todo, para innovar absolutamente. No hay tiempo para empezar de cero, para las orientaciones definitivas, para los principios originarios (MARQUARD I98 IA). No sería humano cuestionar todo, examinando su legitimidad, pues la mortalidad constitutiva no nos deja el tiempo exigido por una innovación convertida maladroitement en fundamento. Una vida finita no puede fundar, como exigiría la prisa innovadora, ni el ser ni el ser así. Solo tenemos tiempo, acaso, para "fundamentar" las desviaciones de lo que ya es. Podemos y debemos innovar hábitos, pero solo a partir de hábitos. No podemos dejar de conectarnos con lo ya sido, nuestra irrenunciable herencia, que nunca es absoluta, sino contingente siempre. La vida breve impide el robinsonismo de la fundamentación última, definitiva y universal, y pide "fundamentaciones" próximas, provisionales y multiversales. Esta ineludible continuidad "hipoléptica", conectiva con lo ya sido, ralentiza la vida, exige la pausa en el cambio, la vida lenta, descargada de absolutos (MARQuard 2000C). Como no podemos transformar todo lo que quisiéramos, por falta de tiempo, estamos vinculados consuetudinariamente a nuestro origen, siempre en permanente (dis)posición de continuidad. No hay porvenir sin provenir. No hay advenimiento sin devenimiento. Lo inicial requiere de lo inercial. La innovación requiere de la preservación (MARQUARD 2000B; 2003).

\section{IV}

Algo así, y para explicar el "progreso" filosófico como inevitable regreso, al objeto de que la Historia de la Filosofía dejase por fin de no ser ni Historia ni Filosofía, ya señaló Ortega y Gasset. Partiendo de la noción de "historicidad", que hace de la Historia la ciencia, por antonomasia, de la transición, asume que lo que la vida humana en todo momento es lo es "en vista de un pasado que en el presente perdura y peractúa” (Ortega y Gasset 2006B, 148). Esto lo lleva a considerar la Historia de la Filosofía como regreso. Ahora bien, el regreso filosófico no lo es a una filosofía ya hecha. El "filósofo auténtico" se encuentra ya "haciendo la suya" (Ortega y Gasset 2006в, 157). Así que el pasado que perdura y peractúa en el filósofo es el del origen permanente del filosofar. Paradoja: una filosofía que se quiere innovadora tiene que rebotar de toda filosofía que esté ahí, negarla y retirarse a la soledad inaugural. Innovar pasa por "volver a comenzar, o lo que es igual, por repristinar la situación en 
que la filosofía se originó” (ORTEGA y GASSET 2006B, 157). La innovación está en "esos renovadores del pensamiento filosófico que no pudiendo ya originarlo lograron reoriginarlo" (Ortega y Gasset 2006b, 157).

La innovación no reside en el pujo de "originalidad", "estúpida preocupación” por diferenciarse de los demás, arriesgándose a no poseer siquiera los modos usuales de pensar y plantear las cuestiones, sino que "es menester que los aniquilemos, que hagamos hacia atrás el movimiento que sus inventores hicieron hacia adelante cuando los crearon" (Ortega y Gasset 2006B, 158). Innovar requiere regreso a la "nada filosófica", a la pura necesidad de filosofar. Esa vuelta al origen sí es, podríamos añadir, "original". Se trata en este recomenzar innovador de ir, en una especie de déconstruction avant la lettre, "desmenuzando, triturando todos los sistemas para asistir de nuevo a su ejemplar nacimiento" (Ortega y Gasset 2006B, 158).

De modo que antes de hacer filosofía hay que deshacer la ya hecha. Hay que repristinar lo que la Filosofía fue originalmente, cuando aún no había tradición. Pero el hecho es entonces que "hacemos siempre nuestra filosofía dentro de tradiciones determinadas de pensamiento en las cuales nos hallamos tan sumergidos que son para nosotros la realidad misma" (OrTEga y GASSET 2006B, 158). La innovación se da sobre el subsuelo intelectual de una tradición. De hecho, lo primero es poner en evidencia la supuesta "evidencia" de la tradición, mostrar que las tradiciones, antes que naturales, son constructos artificiales, "particulares tendencias o ensayos de la mente humana que no son los únicos posibles" (Ortega y Gasset 2006B, 158). La Filosofía es una tradición: la tradición de la in-tradición.

En efecto, no es solo que se filosofe intestinamente a una determinada tradición de pensamiento, que toda labor filosófica particular surja en una particular tradición intelectual, sino que "la filosofía toda es solo una inmensa tradición” (ORTEGa y GASSET 2006B, 159). Lo que ocurre es que lo peculiar de esa inmensa tradición es algo paradójico, pues "la filosofía es el esencial intento de existir fuera de una tradición, esto es, de no vivir en forma de tradicionalidad" (Ortega y Gasset 2006в, 159). Por eso "la verdad es que la filosofía no es, a su vez, sino la tradición de la in-tradición" (OrTEga y GASSET 2006B, 159). Y es que "en el hombre no hay más que sustituciones, y cada una de estas conserva adherido a su espalda el cadáver de aquello que está llamada a sustituir" (OrTega y Gasset 2006B, 160). De manera que la innovación filosófica se dio históricamente cuando volatilizó la existencia en forma de tradición. La tradición vino a sustituir a los instintos, el tradicional vive "instintivamente" la tradición. Solo cuando el "instinto" de la tradición se pierde, puede inaugurarse la tradición filosófica, que por ello es "in-tradición": "Como la pura 'tradición' era un sustituto de los instintos des- 
vanecidos, la filosofía es un sustituto de la 'tradición' rota" (OrTega y GASSET 2006B, 160). Por eso la innovación filosófica parece ir contra la tradición, como su suplantación, cuando no es más que su sucesión, lo que ocupa su puesto vacío.

Por consiguiente, el "re-greso" al origen de su tradición, propio de la innovación, es efectivo "pro-greso". Ciertamente, el retorno no es nostalgia del origen, sino que "al retroceder el filósofo lo hace, desde luego, animado por el propósito de tornar al presente, a él mismo, a su propio y actualísimo pensamiento" (Ortega y GASSET 2006B, 161). Al innovar los sistemas filosóficos se trata de mirarlos no desde un turístico exterior, sino desde el interior, lo cual solo es posible partiendo de la necesidad que los ha engendrado. Así el nuevo sistema, aun siendo otro respecto del anterior, lo conserva en la forma, evitando sus "errores": "De esta manera camina la filosofía tiempo adelante, en dirección al presente, acumulando el pasado e integrándolo con cada innovación" (Ortega y Gasset 2006B, 162).

Que la "innovación oculta" del pensamiento puede que haya que buscarla precisamente en la memoria es asimismo innovación heideggeriana. Esta reside no en una nueva tesis del pensar, sino en un diferente modo de pensar. Esa es la tarea del pensar, consistente en un regreso, de lo inhóspito a lo hogareño, de lo extranjero a lo patrio, de lo ajeno a lo propio. Este retorno a casa no es un paso a nivel, sino un paso de nivel, un paso atrás (Schritt zurück) a lo no pensado, un salto (Sprung): del pensar fundativo a ese modo de pensar "abisal" libre de imposición (Gestell), a "una región totalmente distinta" (HeIdegGer 2002, 10). Este regreso, justo porque requiere un salto, tiene necesidad de su tiempo, el tiempo del pensar (Denken), que es distinto del tiempo del calcular (Rechnen), que doquier insidia actualmente al pensar. La máquina electrónica calcula en un segundo miles de relaciones cuya utilidad, sin embargo, es inesencial (wesenlos). Y es que:

lo que en cualquier momento intentamos pensar, comoquiera lo pensemos, lo pensamos siempre dentro del campo de juego de la tradición (Spielraum der Überlieferung). Ella está viva si libera nuestra reflexión proyectándola en un pensamiento que no tiene nada que ver con el calcular y el planificar. Solo cuando pensando nos volvemos a lo ya pensado, estamos disponibles para lo aún por pensar (HeIDEgGer 2006A, 50) 
Con todas las diferencias específicas señalables (el "salto" excluiría estrictamente la progresividad) el género próximo del planteamiento es coincidente con el orteguiano: no se da (el) "proceso" de(l) pensamiento sin "retroceso". La innovación juega en el campo de la tradición. En la tradición filosófica se oculta, olvidado el ser, su innovación. $Y$ es que pensar es transitivo tras-pasar (HeidegGer 2006в, 71). Y traspasar significa poner al margen el pensamiento conceptual occidental en su étimo de "prensión" (cum-capere, be-greifen), en favor del pensamiento como "(con)memoración”. La gran innovación heideggeriana es salir de la prensil filosofía adquisitiva, esa que busca en el fundamento (Grund) el principio de apoderamiento del ser, un ser convertido reductivamente así en cosa, esa que busca la imposición (Gestell) sobre todas las cosas que, qua fundamento, funda. Se trata, antes al contrario, de deponer esa imposición que impide el traspaso en la falta de fundamento o abismo (Ab-grund).

El tiempo de la innovación como despedida de la imposición tiene lugar en el espacio de la tradición. Esta no se confunde con la efímera "presentificación" del pasado, sino que es el darse del ser, cuyo destino es su envío como anuncio o mensaje, no como ente, sino como diferente. Se explica de este modo el salto innovador, de ese pensamiento que no piensa, porque calcula, al pensamiento memoria, que es memoria del pensamiento (Andenken). La innovación oculta en la tradición no hace entonces del pasado algo irremediablemente pasado, "cosa pasada", como hace el pensamiento conceptual, aferrante, conversor en "cosa" de todo lo que "toca". Por el contrario, el pensamiento (Denken) volcado en la memoria se torna agradecimiento (Danken) (HeIdegGer 2002, 143). Heidegger pone en juego los étimos de pensamiento, ánimo y corazón. Podemos dar fe, además, de que en las lenguas latinas late aún más cordialmente que en las germánicas el recuerdo. La innovación en una u otra tradición arraiga en la conmemoración del corazón tratando de comprender que, toda vez que "la memoria, en el sentido del alma y del corazón, pertenece a la dotación esencial del humano" (Heidegger 2002, 154), en lo que hizo posible el pasado puede que se encuentre la comprensión del porvenir.

\section{VI}

Lentitud y rapidez son cualidades de la vida breve que se requieren contrastivamente, que urden la trama antropológica que permite conjeturar que innovación y preservación son categorías predicables de cualquier humano. Su predicamento rige particularmente para el hombre moderno, pues la modernidad aumenta a la misma vez la velocidad de innovación y la necesidad de lentitud. La aceleración de la innovación conduce a una sobrecarga de innovación, y 
cuanto más lo hace tanto más fuertemente crece la necesidad de compensar las rupturas de la continuidad. De ahí el cultivo de la lentitud, la tradición, la cultura de la continuidad (MARQUARD 2004, 10). Esa falta de tiempo constitutiva del humano, se hace, además, especialmente consecutiva al veloz moderno. La innovación oculta en Filosofía puede explorarse paradójicamente como descarga de la sobrecarga innovativa.

Precisamente la compensatoria "Filosofía del en lugar de" (Philosophie des Stattdessen) marquardiana liga la génesis de las Humanidades y particularmente de la Filosofía (hermenéutica) a la compensación de esa aceleración innovadora que, a su vez, caracteriza a lo moderno. Es esta la tesis de la cultura de la preservación como compensación de la sobrecarga de innovación, tesis que rompe con el prejuicio histórico (principalmente de raigambre positivista) que presenta a las "naturalidades" como un intento (consumado o no) de superar a las Humanidades, como un avance o progreso sobre las (supuestamente falsas) ciencias literarias, las "letras". Brevemente: el éxito de las ciencias naturales exactas, cuyo establecimiento empieza en el siglo XvI, no elimina ni disminuye la necesidad de las ciencias narrativas (MARQUARD 2000A, 63), sino que, antes al contrario, engendra y aumenta su necesidad, haciéndolas inevitables (MARQUARD 1986C). Eso explica que, frente a lo que tan a menudo se difunde, las Geisteswissenschaften sean más recientes que las Naturwissenschaften, pues su periodo de establecimiento comienza dos siglos después. Conforme el mundo va modernizándose, volviéndose así más ahistórico, se tornan más imprescindibles, compensatoriamente, las Humanidades. Cuanto más moderno resulta el mundo, más es lo que hay que contar, y ante la rapidez acelerada del mundo del cambio tecnocientífico, el humano lento es el más preparado: narrare necesse est (MARQUARD 2000A).

$\mathrm{Ni}$ el mundo moderno, rápido, ni los humanos, lentos, pueden suprimirse. Quien renuncia al mundo del cambio acelerado renuncia a irrenunciables medios de supervivencia; quien niega a los lentos humanos reniega de los humanos. La Modernidad comporta la vivencia de ambas cosas: de la rapidez (innovación del porvenir) y de la lentitud (preservación del provenir). No se trata ahora de liberarse de la tensión entre rapidez y lentitud de manera antimoderna, obligando a elegir entre revolución o involución, sino que se trata, antes al contrario, de conservar dicha tensión, preservando la posibilidad de vivir lentamente como humanos en el mundo del cambio acelerado. Por ello "pertenece al mundo moderno, en su rapidez — compensatoriamente- el desarrollo de formas que permiten al humano vivir lentamente dentro de un mundo rápido" (MARQUARD 2000B, 71-2).

Un modo de lograrlo es la Filosofía, precisamente la Filosofía hermenéutica, y, en especial, la "Hermenéutica adaptativa". Efectivamente, cuando 
la caducidad de lo que hay exige retener y no cabe retener, se debe hacer otra cosa: en lugar de retener, hay que hacer lo que compensatoriamente hace la Hermenéutica, hay que interpretar, lo que genera la "Hermenéutica de la restauración en el reino del espíritu” (MARQUARD I995, 70). Hay que interpretar para salvar la comprensibilidad de cosas y textos en contextos aceleradamente cambiantes. Se trata de replicar a la caducidad, lo que se hace imperioso cuanto más se acelera la transformación de la realidad, produciéndose más pérdidas de familiaridad. Es el caso del mundo moderno, donde porvenir y provenir, expectativa y experiencia, innovación y tradición, se desconectan entre sí de modo excepcional. Justo en ese mundo nacen — compensatoriamente, como enseñaba Joachim Ritter- las ciencias del espíritu, o hermenéuticas. Y cuanto más raudo es el incesante cambio hodierno, tanto más urge "el arte de refamiliarizar": la Hermenéutica (MARQuard I98 IC, 126).

En efecto, quizá aquí se esconda la innovación oculta de las Humanidades y particularmente de la Filosofía. Esta puede entenderse como respuesta a la aceleración de las transformaciones del mundo contemporáneo, como réplica a las innovaciones que hacen extraño lo más propio, disociando las expectativas de la vida de las experiencias de la vida (Marquard I986B; I994B). El sentido innovador de la Filosofía estribaría paradójicamente en responder con hermenéutica lentitud compensatoria al frenesí innovador, preservando a la par que actualizando. Así, el objetivo de la carrera filosófica consistiría en aspirar no ya solo a reapropiarnos lo extrańado, sino a apropiarnos de lo extraño. De realizarse este desideratum, podríamos incluso, aunque pueda sonar algo melifluamente, "volver" a los paraísos nunca perdidos, recordando lo no olvidado, pues ni siquiera lo conocíamos. He aquí, en conclusión, la innovativa paradoja: gracias a la Hermenéutica adaptativa, la nuestra no sería solo la época de la caducidad radical, sino, al mismo tiempo, la época de la respuesta radical a esa pregunta que plantea, haciendo de la existencia de cada uno un interrogante siempre abierto, la caducidad: la época "propia" de la Filosofía (MARQuard I98 IC, 127). 


\section{BIBLIOGRAFÍA}

Castro, J.; Echeverría J. y Unceta A. (eds.) 20 i 6, Hidden Innovation. Concepts, Sectors and Case Studies, Donostia: Sinnergiak Social Innovation.

Cunningham S. 2013-I4, Hidden Innovation. Policy, Industry and the creative sector, Queensland: University of Queensland Press.

Chiurazzi G. I999, Il postmoderno. Il pensiero nella società della comunicazione, Turín: Paravia.

Galimberti U. 2000, "L'epoca moderna e il primato della scienza e della tecnica come deriva teológica", Psiche e techne. L'uomo nell'età della técnica, Milán: Feltrinelli, 293-304.

Heidegger M. 1997, Der Satz vom Grund, Frankfurt: Vittorio Klostermann. (Versión original 1957.)

Heidegger, M. 2002, Was heisst Denken?, Frankfurt: Vittorio Klostermann. (Versión original I95 I-52.)

Heidegger, M. 2006A, Der Satz der Identität. Identität und Differenz, Frankfurt: Vittorio Klostermann, 31-50 (Versión original I957.)

Heidegger, M. 2006B, Die onto-theo-logische Verfassung der Metaphysik. Identität und Differenz, Frankfurt: Vittorio Klostermann. (Versión original I95657.)

Marín-Casanova, J. A. 20i6, "Innovación y continuidad. Prolegómenos a la oportunidad de los trabajos académicos finales en Humanidades", en M. Barrios y J. Barrientos (eds.), El trabajo de fin de grado: Teorías y prácticas, Madrid: Visión libros, 29-58

Marquard, O. I98 I a, "Abschied vom Prinzipiellen. Auch eine autobiographische Einleitung", Abschied vom Prinzipiellen. Philosophische Studien, Stuttgart: Philip Reclam, 4-22

Marquard, O. I98 I в, "Der angeklagte und der entlastete Mensch in der Philosophie des 18. Jahrhunderts", Abschied vom Prinzipiellen. Philosophische Studien, Stuttgart: Philip Reclam, 39-66.

Marquard, O. I98 Ic, "Frage nach der Frage, auf die die Hermeneutik die Antwort ist", Abschied vom Prinzipiellen. Philosophische Studien, Stuttgart: Philip Reclam, 117-146.

Marquard, O. I98 ID, "Felix culpa? Bemerkungen zu einem Applikationsschicksal von Genesis 3", en M. Fuhrmann, H. Robert Jauss, y W. Pannenberg (eds.), Text und Applikation. Theologie, Jurisprudenz und Literaturwissenschaft im hermeneutischen Gespräch, Múnich: Wilhelm Fink, 53-71.

Marquard, O. I982, "Geschichte machen zur Entlastung Gottes?”, Schwierigkeiten mit der Geschichtsphilosophie, Frankfurt: Suhrkamp 64-74. 
Marquard, O. I986A, "Universalgeschichte und Multiversalgeschichte", Apologie des Zufälligen, Stuttgart: Philip Reclam, 54-75.

Marquard, O. I986в, "Zeitalter der Weltfremdheit", Apologie des Zufälligen, Stuttgart: Philip Reclam, 76-97.

Marquard, O. I986c, "Über die Unvermeidlichkeit des Geisteswissenschaften”, Apologie des Zufälligen, Stuttgart: Philip Reclam, 98-116.

Marquard, O. I994A, "Zeit und Endlichkeit", Skepsis und Zustimmung, Stuttgart: Philip Reclam, 45-58.

Marquard, O. I994B, "Krise der Erwartung - Stunde der Erfahrung", Skepsis und Zustimmung, Stuttgart: Philip Reclam. 70-92.

Marquard, O. I995, Glück im Unglück. Philosophische Überlegungen, Múnich: Wilhelm Fink.

Marquard, O. 2000A, "Narrare neccesse est", Philosophie des Stattdessen. Studien, Stuttgart: Philip Reclam, 60-65.

Marquard, O. 2000в, "Zukunft braucht Herkunft", Philosophie des Stattdessen. Studien, Stuttgart: Philip Reclam, 66-78.

Marquard, O. 2000C, "Entlastung vom Absoluten. In memoriam Hans Blumenberg", Philosophie des Stattdessen. Studien, Stuttgart: Philip Reclam, 108-20.

Marquard, O. 2003, "Zukunft braucht Herkunft", Philosophische Essays, Stuttgart: Philip Reclam.

Marquard, O. 2004, "Individuum und Gewaltenteilung", Philosophische Studien, Stuttgart: Philip Reclam.

Marquard, O. 20 I 3, Endlichkeitsphilosophisches. Über das Altern, Stuttgart: Philip Reclam.

Natoli, S. 20 I6A, "La metafísica del tragico", L'esperienza del dolore. Le forme del patire nella cultura occidentale, Milán: Feltrinelli, 48-183. (Versión original I986.)

Natoli, S. 20 г6в, "Razionalità e finitezza", L'arte di meditare. Parole della filosofia, Milán: Feltrinelli, 123-28. (Versión original 2004.)

North, M. 20 I 5, Novelty. A history of the new. Chicago: University of Chicago Press.

Ortega y Gasset, J. 2006A, "Apuntes sobre el pensamiento: su teurgia y su demiurgia", Obras completas. Tomo VI, Madrid: Taurus, 3-29. (Versión original I94I.)

Ortega y Gasset, J. 2006B, "Prólogo a Historia de la Filosofía, de Émile Bréhier (Ideas para una historia de la filosofía)", Obras completas. Tomo VI, Madrid: Taurus, 135-71. (Versión original I942.)

Ortega y Gasset, J. 2006c, "Lección X. Estadios del pensamiento cristiano. En torno a Galileo", Obras completas. Tomo VI, Madrid: Taurus, 469-79. (Versión original I947.) 
Vattimo, G. 2000, "Postmoderno: una società trasparente?", La società trasparente, Milán: Garzanti, 5-20. (Versión original 1989.) 